\title{
Affinity of Standard Blood Glucose Level with Skimmed Milk Likeness
}

\author{
Muhammad Imran Qadir and Muhammad Ali Mehdi* \\ Institute of Molecular Biology and Biotechnology, Multan, Pakistan \\ *Corresponding author: Muhammad Ali Mehdi, Institute of Molecular Biology and Biotechnology, Multan, Pakistan
}

\begin{tabular}{ll}
\hline ARTICLE INFO & ABSTRACT \\
\hline
\end{tabular}

Received: 蔧 February 12, 2019

Published: 慧 March 05, 2019

Citation: Muhammad Imran Qadir and Muhammad Ali Mehdi*. Affinity of Standard Blood Glucose Level with Skimmed Milk Likeness. Biomed J Sci \& Tech Res 15(3)-2019. BJSTR. MS.ID.002707.
Persistence of the latest learning was to examine some relation among the normal glucose level of blood and skimmed milk likeness. In the current study, there were 128 participants. All the participants were the students of the Bahauddin Zakariya University Multan, Pakistan. They were the young and their age between 19-24 years. In this 99 were the females and 29 were the male students. We measured their blood glucose level one by one and saved their record. We checked the blood glucose level with help of the blood glucometer. We concluded from this study that the scientific relation exists between blood glucose level and skimmed milk only in males but not in females.

Keywords: Blood Glucose; Skimmed Milk; The Likeness; Blood Glucometer; T-Test; Students; P-Value; Insulin

\section{Introduction}

Blood glucose is the measurement of level of glucose or sugar present in the blood. It is measured with the help of the blood glucometer [1,2]. It is the instrument which is used for the measurement of glucose in blood. The amount of glucose is varying from person to person. When the blood glucose level is high then this leads to a disease known as diabetes. This leads to damage of your body and other diseases. Blood glucose is measured before the meal or before breakfast because when we eat food, the level of carbohydrates increases in our body and process of digestion changes into sugar. And this glucose or sugar diffuses into our blood. As a result, the level of the glucose increases in our blood. Then insulin is secreted to take up sugar from blood and allow to enter the cell. As a result, the blood sugar level goes down in the blood. Skimmed milk is useful for human health. It is drinking in villages mostly. It reduces the burn of liver and very useful in reducing heat production in our body. Due to this impact it is commonly drinking in summer. It is common diet in villages. It is said that after drinking skimmed milk, we enjoy the sound sleep. It strengthens all parts of the body. It has low cholesterol level. Low cholesterol level is fantastic for human health. But high level of cholesterol causes heart attack and high blood pressure. It is rich source of proteins. Proteins contain amino acids which are essential for development and maintenance of feeble muscles. The persistence of the current study was to observe some relation among the normal blood glucose level and the skimmed milk likeness.

\section{Materials and Method}

In the current study, there were 128 participants. All participants were the students of Bahauddin Zakariya University Multan, Pakistan. They were the young and their age between 19-24 years. In this 99 were the females and 29 were the male students. We asked them when they come to check their blood glucose level, they skipped their breakfast. First, we measured their blood glucose level one by one and saved their record. We checked the blood glucose level with help of the blood glucometer. After this, we asked them whether they liked skimmed milk or disliked the skimmed milk. Then we studied their comments and compare it with their blood glucose level.

\section{Measurement of Blood Glucose level}

Before measuring the glucose level of blood, first of all we took the accurate blood glucometer for checking of blood glucose level, disposable strips which was to be inserted to one end of it in the meter and on the other end we placed the blood sample for which glucose level was measured and the sterile needle which is to be inserted on the tip of the figure for taking the blood drop for the sample. Then we set the apparatus and called out the first student, strip was already inserted in the blood glucometer and start the meter for proper functioning and took the sample of blood of the student and placed it on the free end of the strip. After some time, the blood glucometer displayed the reading of glucose present in 
the blood. Then, we tested the glucose level of all the students with this method and saved the readings on the neat white blank paper along with their identification.

Project: The current study was to prepare about the skimmed milk likeness. We analyze the blood glucose level of all the participants with help of blood glucometer and deliberate their views related to the skimmed milk likeness.

Statistical Analysis: Statistical analysis was performed by using the advanced software. It was also known as Statistical Analysis System. SAS Institute developed this advanced software.

\section{Results}

Insinuation of the normal blood glucose level (Mean \pm SD) with skimmed milk likeness is given in the following Table 1.128 students were participated in the current study. All participants were the students of Bahauddin Zakariya University Multan, Pakistan. In 128 students both male and female were present. Their age were19-24 years. In this strength 29 were males and 99 were females. From this study, we came to know that 27 males liked the skimmed milk and the average blood glucose level was 94.11 and only 2 males disliked the skimmed milk and the average blood glucose level was 100 (Table 2). And in 99 females, 74 were liked the skimmed milk and the average blood sugar level was 92.24 and 25 females disliked the skimmed milk and their average blood sugar level was 90.76. The p-value for males were significant and for females this value was non-significant (Table 3). Therefore, we said that the skimmed milk cause impact on blood glucose level only in the males but not in females, this impact occurs. Questionnaire based studies have been given important outcomes in current researches [3-10].

Table 1: Inference of normal blood glucose level (Mean \pm SD) with skimmed milk likeness.

\begin{tabular}{|c|c|c|}
\hline Skimmed milk & $\begin{array}{c}\text { Average Blood Glucose Level } \\
\text { (Males) }\end{array}$ & $\boldsymbol{p}$-value \\
\hline Likeness & $94.11 \pm 8.72$ & $0.01^{*}$ \\
\hline Dis-likeness & $100 \pm 1.41$ & $0.01^{*}$ \\
\hline
\end{tabular}

Table 2: Linkage of normal blood glucose level (Mean \pm SD) with skimmed milk likeness.

\begin{tabular}{|c|c|c|}
\hline Skimmed milk & $\begin{array}{c}\text { Average Blood Glucose Level } \\
\text { (Females) }\end{array}$ & $\boldsymbol{p}$-value \\
\hline Likeness & $92.24 \pm 7.69$ & 0.37 \\
\hline Dis-likeness & $90.76 \pm 6.86$ & 0.37 \\
\hline
\end{tabular}

\section{ISSN: 2574-1241}

DOI: 10.26717/BJSTR.2019.15.002707

Muhammad Ali Mehdi. Biomed J Sci \& Tech Res

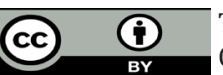

This work is licensed under Creative

Commons Attribution 4.0 License

Submission Link: https://biomedres.us/submit-manuscript.php
Table 3: Correlation of normal blood glucose level (Mean \pm SD) with skimmed milk likeness.

\begin{tabular}{|c|c|c|}
\hline Skimmed milk & $\begin{array}{c}\text { Average Blood Glucose Level } \\
\text { (Both) }\end{array}$ & $\boldsymbol{p}$-value \\
\hline Likeness & $92.74 \pm 7.97$ & 0.41 \\
\hline Dis-likeness & $91.44 \pm 7.04$ & 0.41 \\
\hline
\end{tabular}

\section{Conclusion}

We analyzed from the above study that the scientific relation between the normal blood glucose level and the skimmed milk likeness was not observed in females but in males this relation occurred.

\section{References}

1. Qadir MI, Malik SA (2010) Comparison of alterations in red blood cell count and alterations in hemoglobin concentration in patients suffering from rectal carcinoma undergoing 5-fluorouracil and folic acid therapy. Pharmacologyonline Nl 3: 240-243.

2. Qadir MI, Noor A (2018) Anemias Rare \& Uncommon Diseases. In Qadir MI, Noor A(eds.) Cambridge Scholars Publishing. Newcastle England.

3. Qadir MI, Javid A (2018) Awareness about Crohn's Disease in biotechnology students. Glo Adv Res J Med Medical Sci 7(3): 062-064.

4. Qadir MI, Saleem A (2018) Awareness about ischemic heart disease in university biotechnology students. Glo Adv Res J Med Medical Sci 7(3): 059-061.

5. Qadir MI, Ishfaq S (2018) Awareness about hypertension in biology students. Int J Mod Pharma Res 7(2): 8-10.

6. Qadir MI, Mehwish (2018) Awareness about psoriasis disease. Int J Mod Pharma Res 7(2): 17-18.

7. Qadir MI, Shahzad R (2018) Awareness about obesity in postgraduate students of biotechnology. Int J Mod Pharma Res 7(2): 14-16.

8. Qadir MI, Rizvi M (2018) Awareness about thalassemia in post graduate students. MOJ Lymphology \& Phlebology 2(1): 14-16.

9. Qadir MI, Ghalia BA (2018) Awareness survey about colorectal cancer in students of M. Phil Biotechnology at Bahauddin Zakariya University, Multan, Pakistan. Nov Appro in Can Study 1(3): NACS.000514.

10. Qadir MI, Saba G (2018) Awareness about intestinal cancer in university student. Nov Appro in Can Study 1(3): NACS.000515.

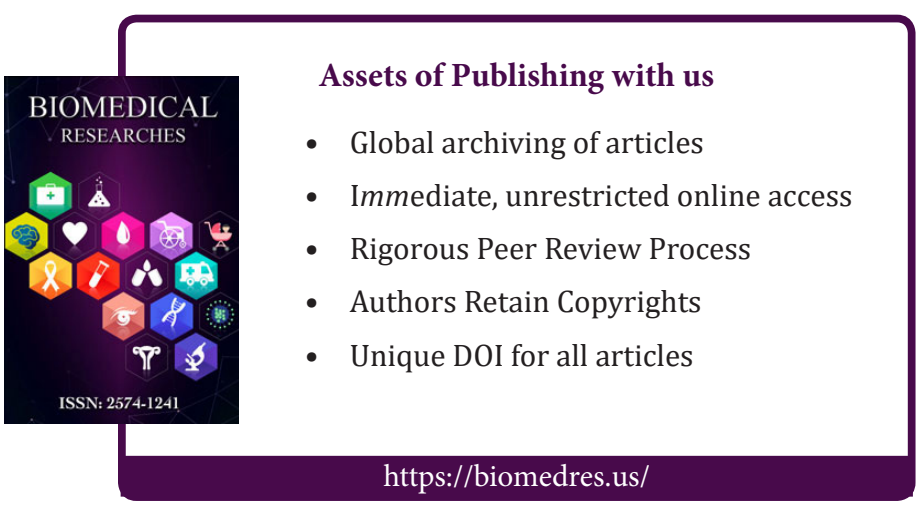

